\title{
Three positive feedback mechanisms for ice-sheet melting in a warming climate
}

\author{
Diandong REN, ${ }^{1}$ Lance M. LESLIE ${ }^{1,2}$ \\ ${ }^{1}$ Australian Sustainable Development Institute, Curtin University, Perth, Western Australia 6845, Australia \\ E-mail: rendianyun@gmail.com \\ ${ }^{2}$ School of Meteorology, University of Oklahoma, 120 David L. Boren Blvd., Suite 5900, Norman, Oklahoma 73072, USA
}

\begin{abstract}
Three positive feedback mechanisms that accelerate ice-sheet melting are assessed in a warming climate, using a numerical ice model driven by atmospheric climate models. The Greenland ice sheet (GrIS) is the modeling test-bed under accelerated melting conditions. The first feedback is the interaction of sea water with ice. It is positive because fresh water melts ice faster than salty water, owing primarily to the reduction in water heat capacity by solutes. It is shown to be limited for the GrIS, which has only a small ocean interface, and the grounding line of some fast glaciers becomes land-terminating during the 21 st century. The second positive feedback, strain heating, is positive because it produces further ice heating inside the ice sheet. The third positive feedback, granular basal sliding, applies to all ice sheets and becomes the dominant feedback during the 21st century. A numerical simulation of Jakobshavn Isbræ over the 21 st century reveals that all three feedback processes are active for this glacier. Compared with the year 2000 level, annual ice discharge into the ocean could increase by $\sim 1.4 \mathrm{~km}^{3} \mathrm{a}^{-1}$ ( $\sim 5 \%$ of the present annual rate) by 2100 . Granular basal sliding contributes $\sim 40 \%$ of this increase.
\end{abstract}

\section{INTRODUCTION}

The 2007 Intergovernmental Panel on Climate Change (IPCC) Fourth Assessment Report (AR4) highlights the melting of the Greenland ice sheet (GrIS) as a critical, but still poorly understood, process in shaping global climate change in the 21 st century. The accelerated GrIS mass loss observed since the 1990s (e.g. Velligna and $\mathrm{Wu}, 2004$; Velicogna, 2009; Rignot and others, 2011) was not captured by any ice-sheet model in the IPCC AR4. This led to IPCC underestimates of global sea-level rise (SLR) projections for the 21 st century of up to $0.2 \mathrm{~m}$ (Meehl and others, 2007). At present, the astronomical background is stable and there are no global forcing processes outside the climate system (e.g. changes in solar activity; large volcanic eruptions that alter radiative forcing) to contribute to accelerated melting of the GrIS. For example, the eruption of the Eyjafjallajökull (Iceland) volcano in 2010 did not slow the GrIS melting rate.

Therefore, the dramatic ice mass loss over the past decade, which reached $\sim 0.7 \mathrm{~mm} \mathrm{a}^{-1}$ sea-level contribution in 2010, is probably an impact of climate warming. The warming is not reversible just by a few opposing events, such as several years of lower annual mean temperatures. The climate-system components most relevant to ice-sheet evolution occur in the atmosphere, lithosphere and hydrosphere. Internal processes, or processes within the cryosphere, may also have contributed to the recently observed accelerated ice melting.

This study examines three important, but previously overlooked, self-perpetuating, positive feedbacks between ice warming and ice-sheet melting. Bindschadler (2006) proposed that ocean warming triggers accelerated glacier melting. The hypothesis is supported by the acceleration of outlet glaciers (Joughin and others, 2004; Howat and others, 2007; Stearns and Hamilton, 2007) occurring at approximately the same time as a warming trend began in the subpolar North Atlantic Ocean, adjacent to Greenland's southeastern and western sectors. The warming apparently produces increased melting at the ice/ocean interface
(Thomas, 2004; Nick and others, 2009). Adding weight to the hypothesis, recent observational studies (Rignot and others, 2010; Straneo and others, 2010) provide evidence of subtropical waters offshore of Greenland (e.g. Bersch and others, 2007; Myers and others, 2007; Thierry and others, 2008).

Accelerated melting of the GrIS and thawing of the permafrost could also affect the freshwater discharge to the subpolar Atlantic and the Arctic Oceans (Peterson and others, 2006; Serreze and others, 2006), which are the source regions for the North Atlantic Deep Water. The associated change of salinity can have a large impact on the strength of the Atlantic Meridional Overturning Circulation (AMOC), as described by Broecker and others (1985), Manabe and Stouffer (1999), Oka and Hasumi (2004) and Peterson and others (2006). The AMOC plays a crucial role in the global redistribution of heat and fresh water (Stocker, 2002; Stouffer and others, 2006; Hu and others, 2010). It pulls warmer, saltier surface water from the other oceans to the subpolar North Atlantic, where it descends in the far north to form cold deep water, after losing its heat and exchanging physical properties with the polar environment. The cold water flows southward at depth to complete the loop. Possible changes in the AMOC as the climate warms also drive the increased focus on the role of oceans in ice melting. In situ measurements in harsh subpolar environments are limited (Rignot and others 2010; Straneo and others 2010) but show that subtropical Atlantic water can reach the western and southeastern Greenland fjords and cause direct submarine melting at the glacier terminus. They support another hypothesis concerning the recent acceleration of outlet glaciers from the GrlS: that ocean heat transport causes enhanced melting at the front of the glacier, leading to ice thinning and ungrounding of the terminus and ice-flow acceleration (Bindschadler, 2006).

Recent studies suggest that salinity anomalies in the tropical Atlantic can propagate northward to the subpolar Atlantic and influence the strength of the AMOC (Vellinga 
and Wu, 2004; Saenger and others, 2009). Salinity changes occur in response to atmospheric forcing fluctuations such as changes in precipitation and winds (Häkkinen, 2007) and inter-(ocean-)basin water exchanges (Hu and others, 2010). Salinity anomalies in the North Atlantic are mainly caused by changes in the Arctic outpouring current, ice melting, precipitation and river discharges. The Greenland Sea upper ocean (primarily the upper $200 \mathrm{~m}$ mixing layer) has become fresher and warmer since 1980 (Karstensen and others, 2005). Present understanding and predictive skill remain low (Huang and others, 2007), especially concerning the influence of adjacent continents (Richter and Xie, 2008). The salinity feedback process is complex, due primarily to the usually opposing contributions to thermal and dynamical properties of sea water. This study calculates the net contribution of salinity change and shows that the outcome is a positive feedback on ice melting, for water-terminating fast glaciers.

Increased ice temperatures lead to a second positive feedback process, namely increased internal friction (strain) heating. This is a positive feedback because it leads to further heating of the ice from inside the ice sheet. Strain heating provides a 'faster' pathway for heat to be transferred within the ice than is possible purely by diffusion. A time-invariant link is presented to describe the strain-heating relationship with ice temperature. Using this relationship, changes in strain heating in a future warming climate can be estimated.

The third positive feedback is granular basal sliding (Ren and others, 2011a). This feedback is persistent, and unlike the ocean-ice feedback it also applies to the land-terminating part of an ice sheet. Both global compilations (Hay and others, 1988) and studies of specific regions (Hay and others, 1989) show that increases in sediment accumulation during the past $2 \times 10^{6}$ years and climate change played an important role in the erosion process (Molnar, 2001). Glaciers apparently erode more effectively than rivers under otherwise similar conditions (Hallet and others, 1996; Ren and others, 2011a,b). Ren and others (2011a,b) showed that a warming climate and granular material production together form a positive feedback through ice physics.

This paper is structured as follows. The three feedback mechanisms are examined for the GrIS, using the recently developed SEGMENT-ice model (Section 2.1). The input static geological and ice geometry data and climate forcing from global climate models are described in Section 2.2. The results of the numerical simulations, which include all three feedback mechanisms, are presented in Section 3. In particular, the evolution of Jakobshavn Isbræ is simulated by SEGMENT-ice to trace significant changes of this glacier's flow in the 21 st century. The particular bedrock geometry, ice thickness profile and geological location of Jakobshavn Isbræ mean that all three feedback mechanisms are salient for its evolution. Section 4 discusses the results of the numerical model simulations, and Section 5 provides concluding comments.

\section{DATA AND METHODOLOGY}

The surface topography (digital elevation map (DEM)) and bedrock topography are from Bamber and others (2001). The DEM is used to calculate strain, stress and surface slope. The horizontal gradients of the surface DEM are the forcing terms for the momentum equations. The surface topography slope is also used to estimate the meltwater redistribution. Here the $1 \mathrm{~km}$ resolutions of ice thickness and the DEMs are used. Geothermal heat flux, because it works steadily for an extended period, is an important control on ice-sheet temperature profiles. Geothermal heat fluxes were developed by Shapiro and Ritzwoller (2004). In addition to these static datasets, which are invariant on the century timescale of interest here, atmospheric parameters are also needed as inputs. These climate parameters are obtained from coupled general circulation models (CGCMs), which are commonly referred to as 'climate models'.

\subsection{The ice dynamics model}

The thermomechanically coupled scheme is designed and implemented as one integral component of a scalable and extensible geofluid modelling system, SEGMENT (Ren and others, 2009). By synthetically solving the threedimensional conservation equations for mass, momentum and energy under multiple rheological relationships, SEGMENT provides prognostic fields of the driving and resistive forces, and describes the flow fields and the dynamic evolution of thickness profiles of the medium (ice in this case). The inner ice domain follows the Glen (1955) ice rheology. A granular layer is allowed between ice and unfractured bedrock. The granular viscosity parameterization is based on Jop and others (2006). Many ice models use only ice-over-bedrock configurations. In contrast, SEGMENT-Ice has an ice-granular-material-bedrock configuration for regions with granular material present, mostly for regions with significant basal melting. Ren and others (2011a) provide the formulation of the granular law; justification of the granular layer; the omission of isostatic rebound; discussion of consistent choices of ice constitutive law and Weertman basal sliding; new approaches in parameterizing surface melting and runoff; the crevasse enhancement of basal sliding; and sea-water-ice interaction at the calving front.

Parameterization of viscosity is critical for ice creep. SEGMENT-ice has two improvements over Glen's ice rheological law (Hooke, 1981; Van der Veen, 1999), factoring in the flow-induced anisotropy and granular basal conditions. The flow enhancement by re-fabricating (Wang and Warner, 1999) is implemented, so older ice, farther from the Summit, is easier to deform. SEGMENT-ice also allows a lubricating layer of basal sediments between the ice and bedrock which enhances ice flow and forms a positive feedback for mass loss in a warming climate (MacAyeal, 1992; Alley and others, 2003; Ren and others, 2010; Fig. 2, further below). Because the ocean temperature is higher than that around Antarctica, there are no ice shelves around Greenland. However, there are several water-terminating fast glaciers around the periphery of GrlS, such as Jakobshavn (J), Kangerdlugssuaq $(\mathrm{K})$, Helheim $(\mathrm{H})$ and Petermann $(\mathrm{P})$ glaciers. In SEGMENT-ice, ocean-ice interactions are parameterized so that the depressing of the freezing point by soluble substances, the salinity dependence of ocean water thermal properties and the ocean-current-dependent sensible heat fluxes are all included.

As the climate warms, increased air temperature through turbulent sensible heat-flux exchange increases surface melting and runoff. Similarly, changes in precipitation affect the upper boundary input to the ice-sheet system. For the period of interest here, major ice temperature fluctuations are near the upper surface of the GrIS. The strain rate, however, can be large near the bottom, so SEGMENT-ice has a 31vertical-level, stretched grid to better differentiate the bottom 
and near surface. The uppermost layer is $0.45 \mathrm{~m}$ thick near the GrIS Summit (e.g. gridlines in inset of Fig. 1), fine enough to simulate the upper surface energy state on a monthly timescale. Because of its location, the GrIS is an important contributor to eustatic SLR, ocean salinity and North Atlantic thermohaline circulation (Alley, 2000). In SEGMENT-ice, the total mass loss comprises surface mass balance and the dynamic mass balance due to ice flow divergence.

In ice flow, inertial and viscous terms counteract pressure gradient forces. The full Navier-Stokes equations are used in the momentum equations of SEGMENT-ice. Because of comparably large aspect ratios, ice streams and surrounding transition zones are the areas where a full Stokes model is most needed (Zwinger and others, 2007). Finally, there are two important improvements in the SEGMENT-ice numerics. Recently, the Robert-Asselin-Williams (RAW; Williams, 2011) filter has been adopted, in place of the more commonly used Asselin time filter. This treatment has improved both spin-up and the conservation energetics of the physical processes. A second improvement is in the optimization procedure of the data assimilation code. A quasi-Newton minimization scheme is now used instead of the conjugate-gradient scheme which is less robust and less efficient for real, noisy data.

Relevant to the first positive feedback mechanism identified in this study, SEGMENT-ice has a unique iceshelf component that considers the heat transfer between ice and the surrounding sea water as an aqueous solution of five major electrolytes $\left(\mathrm{Cl}^{-}, \mathrm{Na}^{+}, \mathrm{Mg}^{2+}, \mathrm{SO}_{4}{ }^{2-}\right.$ and $\left.\mathrm{Ca}^{2+}\right)$ and the subsequent ice formation and melting at the interface. Sea water is an aqueous solution of many electrolytes. The physical properties of this solution that are relevant for heat transfer are thermal conductivity, $\lambda$, density, $\rho$, heat capacity under constant pressure, $c_{p}$, and kinematic viscosity, $\nu$. The heat transfer from liquid (the sea water) to solid (the ice in contact with sea water), $Q_{\mathrm{h}}$, is also related to the liquid flow property, measured as Prandtl number and Grashof number, to measure whether the natural or forced heat conductance dominates. Under typical conditions in the polar seas surrounding Greenland, a turbulent boundary layer is a more accurate approximation. The ocean currents around Greenland are complicated. The East and West Greenland Currents transport cold and fresher water that meets the subtropical warm and saltier waters from the Irminger Current, a topographically steered branch of the North Atlantic Current. Fresh water occurs in the vicinity of the glacier environment in the upper $100 \mathrm{~m}$, but strong mixing and density-driven circulations are plentiful at greater depths. Recent observations confirm that there are vigorous circulations even under a glacier terminus (e.g. Rignot and others, 2010; Straneo and others, 2010). Thus, we propose that

$$
Q_{\mathrm{h}}=\rho c_{p} C_{\mathrm{H}}\left(T_{1}-T_{\mathrm{s}}\right) u,
$$

where $\rho$ is sea-water density, $c_{p}$ is specific heat of sea water, $u$ is sea-current speed, $T_{1}$ is sea-water temperature, $T_{\mathrm{s}}$ is ice surface temperature and $C_{\mathrm{H}}$ is a stability-dependent heat transfer coefficient $\left(\left(3 \times 10^{-6}\right)-10^{-5}\right)$. Note that $\rho, c_{p}$ and $C_{\mathrm{H}}$ are all functions of salinity $S$ (the molar fraction of electrolytes over water).

There is a problem concerning freezing-point depression by electrolytes in solvent. When the solution reaches solid (ice)-liquid (sea-water) equilibrium, the chemical potential of the solvent is equal between the liquid and the solid

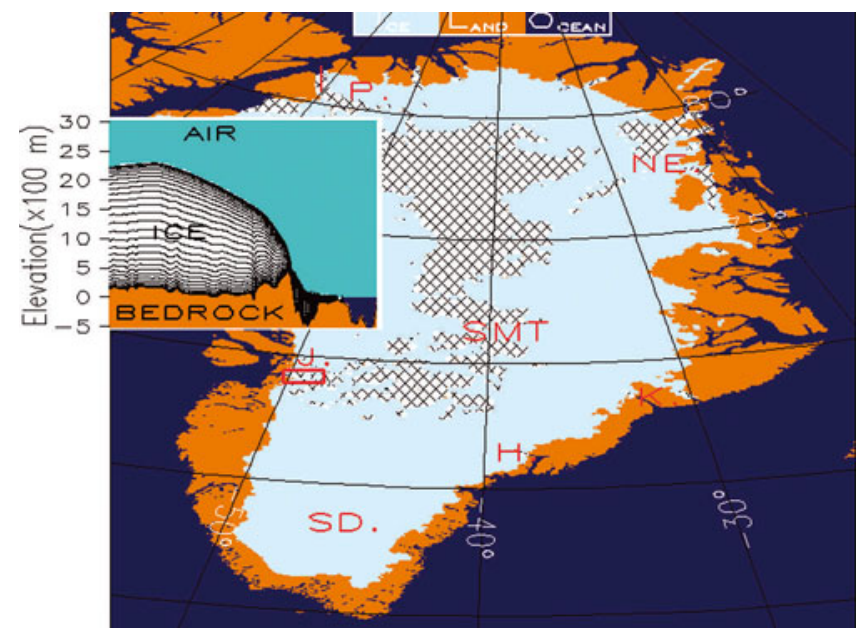

Fig. 1. Land-cover mask for the Greenland ice sheet. The locations of Jakobshavn (J.), Kangerdlugssuaq (K.), Petermann (P.) and Helheim (H.) glaciers, the northeast Greenland ice stream (NE.) and the Summit (SMT) are labeled. Hatched areas are regions with ice loads but with bottom elevations lower than the present sea level. Red box delimits the $1 \mathrm{~km}$ simulation of Jakobshavn Isbræ in Figure 6. Inset is a zoomed Petermann Glacier (south is to the left), a vertical cross-section along the vertical red line.

phase (Raoult's law). The molar Gibbs free energy for liquid phase is defined as

$$
\mu^{\prime \prime}=\mu_{0}^{\prime \prime}(T, P)+R^{*} T \ln a,
$$

where $T$ is temperature, $P$ is pressure, $R^{*}$ is the ideal gas constant and $a$ is the activity of the solvent. The chemical potential for the solid state is similarly defined as

$$
\mu^{\prime}=\mu_{0}^{\prime}(T, P) \text {. }
$$

According to the Gibbs-Helmholtz equation,

$$
-\left(h_{0}^{\prime \prime}-h_{0}{ }^{\prime}\right) \frac{\mathrm{d} T}{T^{2}}+R^{*} \mathrm{~d}(\ln a)=0,
$$

where $h_{0}{ }^{\prime \prime}$ is the enthalpy of pure water and $h_{0}{ }^{\prime}$ is the enthalpy of pure ice. Thus $\Delta h(T)=\left(h_{0}{ }^{\prime \prime}-h_{0}{ }^{\prime}\right)$ is the enthalpy change of fusion and can be parameterized linearly around the triple point along an isotherm:

$$
\Delta h(T)=\Delta h\left(T_{\mathrm{f}}\right)+\left(c_{p}{ }^{\prime \prime}-c_{p}{ }^{\prime}\right)\left(T-T_{\mathrm{f}}\right) .
$$

Here $c_{p}=\left.\frac{\partial h}{\partial T}\right|_{p}$ is heat capacity and $I^{\prime \prime \prime}{ }^{\prime}=\Delta h\left(T_{\mathrm{f}}\right)$, where " denotes liquid states and ' denotes solid states, is usually termed latent heat of fusion. Integrating Equation (4) along an isotherm from the triple point of pure water, $T_{\mathrm{f}}$, to an arbitrary temperature $T$, gives

$$
I^{\prime \prime}-^{\prime}\left(\frac{1}{T_{\mathrm{f}}}-\frac{1}{T}\right)-\left(c_{p}{ }^{\prime \prime}-c_{p}{ }^{\prime}\right)\left(1-\frac{T_{\mathrm{f}}}{T}+\ln \frac{T_{\mathrm{f}}}{T}\right)=R^{*} \ln a .
$$

For a given value of a (molar concentration of solutes), Equation (5) can be solved numerically to obtain an equilibrium temperature, T. In SEGMENT-ice, Equation (5) is used in determining phase change of ice in contact with sea water. This parameterization is relevant for waterterminated glaciers (e.g. Helheim Glacier) and ice streams.

\subsection{Climate model forcing}

This study investigates both atmospheric and oceanic driving of GrIS melting, especially for ocean-terminating fast outlet glaciers. The key controls on melting, such as volume and 


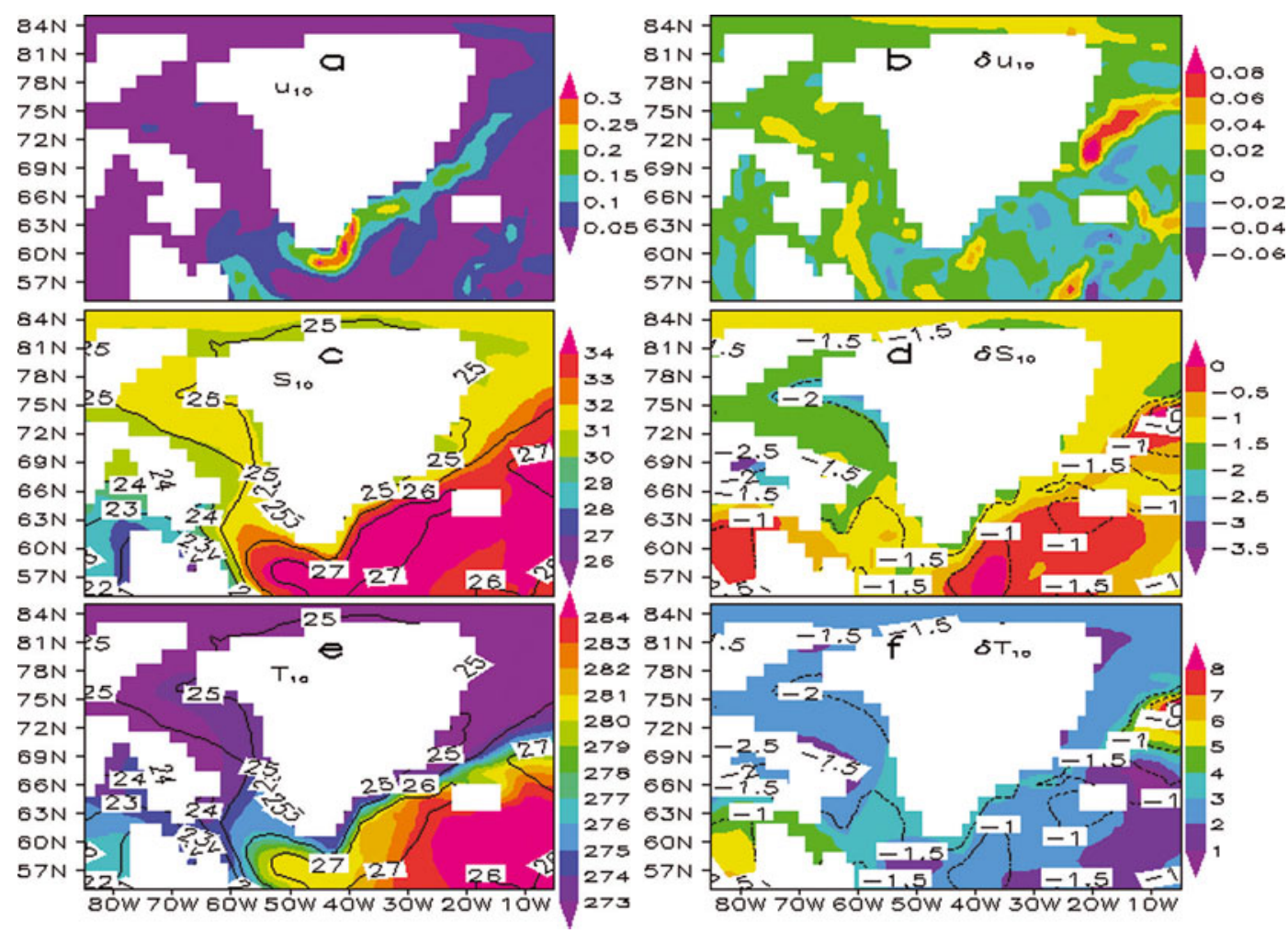

Fig. 2. Oceanic forcings shown at $10 \mathrm{~m}$ depth. (a) Flow speed $\left(\mathrm{m} \mathrm{s}^{-1}\right)$, (c) salinity (psu) and (e) potential temperature (K), with changes over the 21 st century shown respectively in (b), (d) and (f). Contours in (c) and (e) are potential density $\left(\mathrm{kg} \mathrm{m}^{-3}\right.$, difference from $1000 \mathrm{~kg} \mathrm{~m}^{-3}$ ) and are the same in both panels. Contours in (d) and (f) are changes in potential density.

properties of subtropical water intrusion, the alongshore wind patterns and the associated changes in weather patterns, likely are intertwined. Therefore, CGCMs provide the predicted atmospheric and oceanic parameters to drive the SEGMENT-ice model.

Refining the horizontal model resolution improves the regional simulations of precipitation (Genthon 1994; Ohmura and others, 1996). Thus, two CGCMs with relatively fine horizontal resolutions, the NCAR CCSM3 (Collins and others, 2006; $\sim 4^{\circ}$ ) and MIROC3.2 (Hasumi and Emori, 2004; $\sim 125^{\circ}$ ), were chosen. These CGCMs provide all input variables needed by SEGMENT-ice, i.e. monthlymean near-surface air temperature, precipitation rate, surface (skin) temperature, surface pressure, $2 \mathrm{~m}$ wind speed and all six components of radiation for determining the surface energy balance. For ice melting, SEGMENT-ice (Ren and others, 2011b) uses an energy-balance scheme instead of the positive degree-day (PDD) schemes which are popular in ice models applied to paleoclimate studies. Estimates of the warming effects on ice-sheet melting are based on the IPCC Special Report on Emissions Scenarios (SRES) A1B scenario, which assumes a balanced energy source in a future world of rapid economic growth. This scenario is chosen primarily because it reflects the most recent trends in the driving forces of emissions.

In addition to atmospheric parameters, to investigate the ice-ocean interactions at Jakobshavn, Kangerdlugssuaq, Helheim and Petermann glaciers, the ocean flow speed, $|\vec{V}|$, potential temperature, $T$, salinity, $S$, and density, $\rho$, are also needed. Density is not an independent property since it is a function of temperature, salinity and pressure. That is, it is a function of salinity and potential temperature. For the outlet glaciers north of $70^{\circ} \mathrm{N}$, the CCSM and MIROC-hires ocean model outputs at $0,10,20,30,50,75$ and $100 \mathrm{~m}$ depths are interpolated to SEGMENT-ice grids. The top $100 \mathrm{~m}$ of sea water has similar spatial patterns of the physical properties and similar temporal variations. Therefore plots are shown only of the near-surface (10 m depth) ocean parameters (Fig. 2). For Helheim Glacier, which resides in the Sermilik Fjord, the $1 \mathrm{~km}$ resolution icethickness data obtained from the SeaRISE project (http:// websrv.cs.umt.edu/isis/index.php/Main_Page) indicate that the terminus depth is $\sim 700 \mathrm{~m}$, close to the estimation of Thomas and others (2000). Oceanic parameters up to $1000 \mathrm{~m}$ are used for this glacier. At present, none of the climate models has a coupled land-ice component, so the limited salinity changes (Fig. $2 \mathrm{~b}$ and e) are due primarily to precipitation changes and changes in river routing and, to a lesser degree, circulation adjustments. The model (Fig. 2f) shows significant warming of ocean water around the GrlS from the surface to $100 \mathrm{~m}$.

\section{RESULTS}

\subsection{Impacts of ocean water interactions}

Freezing-point temperatures at the four selected fast glaciers are respectively $-1.6,-1.7,-1.65$ and $-1.66^{\circ} \mathrm{C}$ at Jakobshavn, Helheim and Petermann glaciers and the northeast Greenland ice stream. Figure 3 shows the projected additional ice retreat due to interactions with sea water (the combined results of water warming and freshening). By 2100 , the calculated net retreats from ocean contribution are $327,87,57,728$ and $682 \mathrm{~m}$ for the northeast Greenland ice stream and Petermann, Kangerdlugssuaq, Helheim and Jakobshavn glaciers respectively. To the southeast of the GrIS (e.g. Kangerdlugssuaq and Helheim glaciers), the ocean 


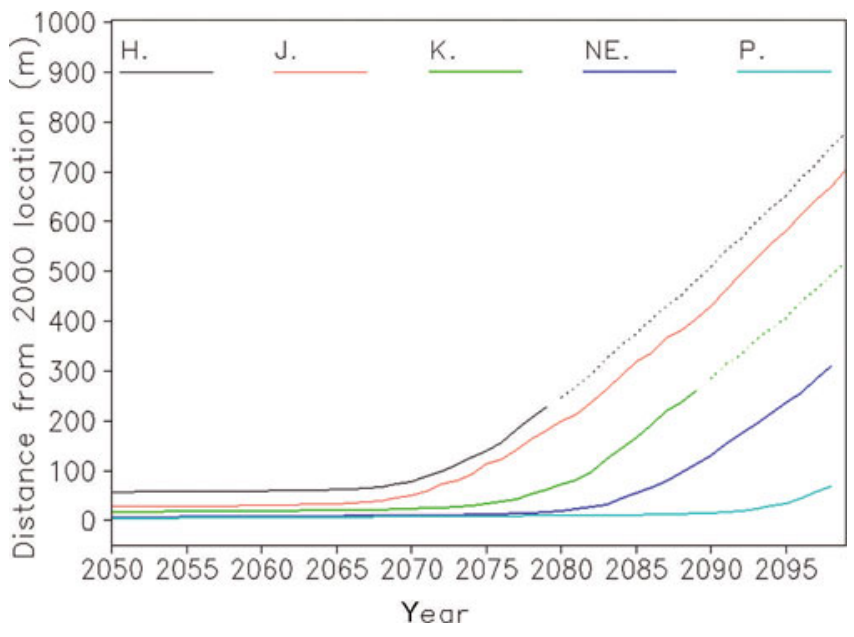

Fig. 3. Terminus retreat for five fast glaciers at the margin of the GrIS: Helheim (H.), Jakobshavn (J.) and Kangerdlugssuaq (K.) glaciers, the northeast Greenland ice stream (NE.) and Petermann Glacier (P.). The retreat is perpendicular to the interface. Dotted lines indicate that the glaciers are likely to be totally land-terminated by that time, and the direct ocean effects will suddenly disappear.

salinity is already low (28 psu at surface level) and the contributions from water freshening are small $(<5 \%)$. At Jakobshavn Isbræ, it can be as large as $15 \%$. For the same temperature differences between ice and liquid/gas, water is five times more efficient in melting ice than air, due to its higher bulk heat-transfer coefficient. Although for ocean water the heat transfer coefficient, $C_{\mathrm{H}}$, is three orders of magnitude smaller than for air, its density is three orders of magnitude larger than for air, and its specific heat is four times larger than for air. Hu and others (2010) prove that the surface water salinity can fluctuate about 2 psu on glacial timescales. If current climate change is more significant than historical natural climate changes, a sensitivity experiment is performed assuming a 5 psu fluctuation of the upper $1000 \mathrm{~m}$ of sea water. If other factors are unchanged, the contribution from the freshening of sea water is $<3 \%$ of the sensible heat transfer between ice and sea water.
Note that the additional melting due to freshening is small compared with that of ocean water warming. The ocean water influence on the GrIS outlet glaciers is limited because the interfaces are only a small fraction of the entire grounding line and because some of the water-terminating glaciers will be land-terminating during the 21st century (e.g. Kangerdlugssuaq and Helheim glaciers in Fig. 3). From Figure 1, the bedrock elevations for the outlet glaciers are below sea level. There are always ocean/ice interfaces before the grounding line retreats to locations above sea level.

At the base of water-terminating glaciers (Fig. 4), the interface is usually slanted so the water cavity is wedge-like. The angle, $\theta$, can be small (typically several degrees) to form ice shelves, or moderate to form landlocked ice. For numerical modelling, we set the stress tangential to the water/ice interface to be zero. The normal stress is the hydrostatic stress of the water at that depth. Inside the ice, the imbalance of stresses is compensated by viscous creep. Thermodynamically, turbulent sensible heat fluxes and phase changes are allowed at the interface. As the ice always melts from below, the tongue is lowered to meet the hydrostatic balance requirement. In SEGMENT-ice, the yield strength of the solid ice is prescribed so that when the yield strength is exceeded, crevasses occur. As ice is brittle, even at temperatures close to the melting point, a lowering of the ice tongue is usually accompanied by cracking. The reverse is true when ice accumulates at the interface. The actual fluctuation of the grounding line location is a dynamic balance between melting/condensing and flow divergence. To convert retreating into grounding-line retreat, the angle effects should be factored in, as they affect the melting fraction contribution. For Helheim Glacier, the grounding line retreat reaches $80 \mathrm{~km}$ by the end of this century from the ocean contribution alone, and may render this glacier totally land-terminated by that time.

The GrIS meltwater routing into surrounding waters might have an effect on the AMOC analogous to the inter-basin freshwater transfer effects (Molnar, 2008). For example, relatively fresh North Pacific water can enter the Arctic Ocean through the Bering Strait and go further into the

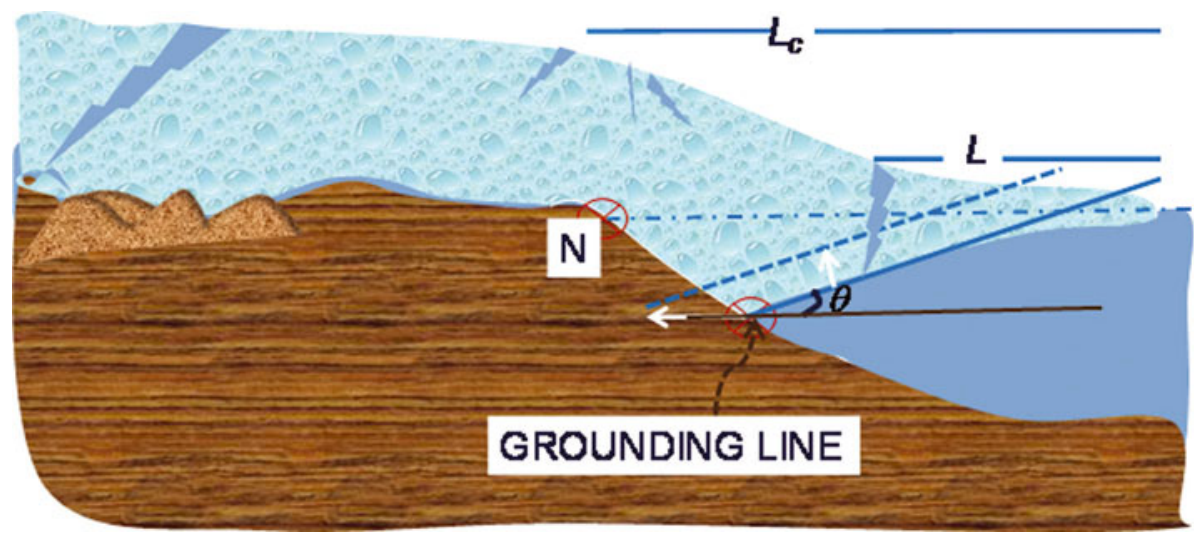

Fig. 4. Schematic of a water-terminating glacier. The water/ice interface cavity is usually wedge-shaped with angle $\theta$. The model calculates the ice retreat normal to the interface. The grounding line retreat should be estimated with a multiplicative factor $1 / \tan \theta$ which can be up to $\mathrm{O}\left(10^{2}\right)$ in magnitude. The portion that extends to sea $\left(L_{c}\right)$ is limited by climate conditions, primarily by ice mass turnover rate and ocean temperature. Ice is brittle because its low melting-point diffusivity is $\sim 10^{-15} \mathrm{~m}^{2} \mathrm{~s}^{-1}$. The limiting length $L$ for shelf break is a good indicator of grounding line retreat. $\theta$ increases as the climate warms. If the ice sheet is primarily land-based, the ocean's effect diminishes as the grounding line retreats to ground above sea level (point $\mathrm{N}$ ). 


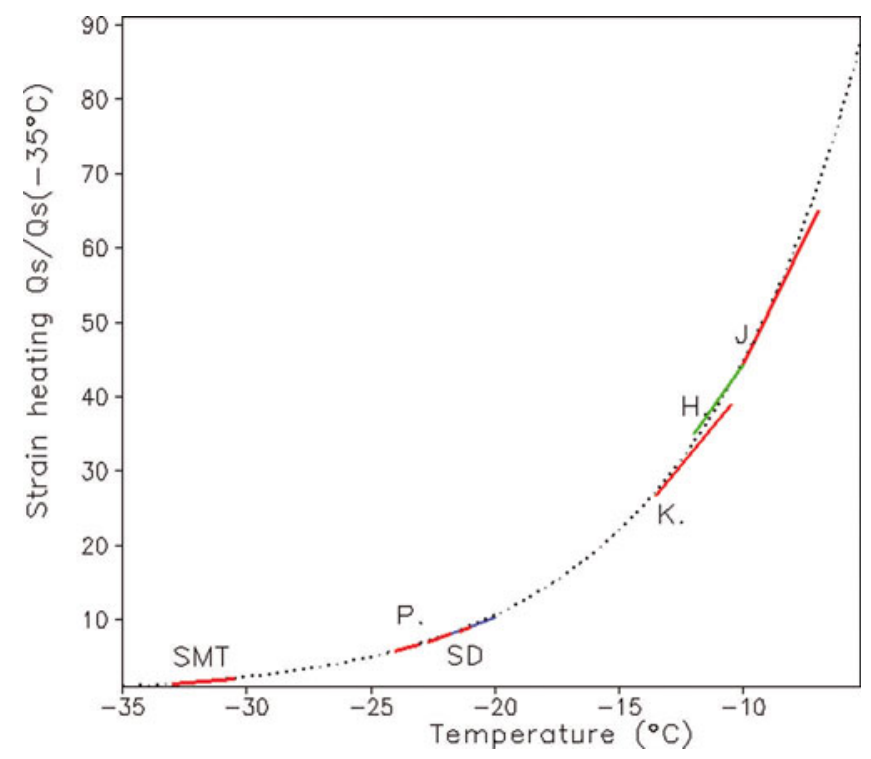

Fig. 5. Strain-heating rate relative to the rate at $-35^{\circ} \mathrm{C}$ at six stations: Summit (SMT), Petermann Glacier (P.), Southern Dome (SD), Kangerdlugssuaq (K.), Helheim (H.) and Jakobshavn (J.) glaciers. The starting point corresponds to the value in 2000; the end point corresponds to the value in 2100 . To differentiate clearly between locations, the Petermann Glacier data are indicated by a red dashed line, the Southern Dome data by a blue line, and the Helheim Glacier data by a green line.

North Atlantic through the clockwise Arctic Ocean surface current. Hu and others (2010) found that the opening and closing of the Bering Strait corresponds well with the eustatic sea-level oscillations on subglacial temporal scales $(\sim 20 \mathrm{ka})$. This is not explicable by solar radiation and albedo positive feedback alone, as they both vary smoothly within the $116 \mathrm{ka}$ last glacial period. This identified self-constraint mechanism is the strengthening and slackening of the AMOC. When the AMOC is strong (e.g. when the Bering Strait is completely shut down by a drop in sea level or is frozen when the sea water is relatively shallow) the northward heat transfer is strong and persists for many thousands of years. This will cause a drastic shrinkage of ice sheets and an associated global SLR. The opposite phase is a strong mixing of surface water from the Arctic Ocean and a weakened AMOC resulting in a colder environment that favours expansion of glaciers and ice sheets. At present, the runoff water from the GrIS melting may act in a similar way to weaken the AMOC, but to a much smaller extent when compared with Pacific-Atlantic water mixing. It is a checking mechanism for enhanced melting as climate warms (i.e. a negative feedback). However, the $\mathrm{Hu}$ and others (2010) results cannot be taken literally in the current human-induced climate-warming context. The current warming trend is not comparable with the natural oscillatory climate variability, as it has a human component with an upward trend. This implies a net total energy build-up within the climate system. Even when the AMOC weakens, atmospheric components may assume the poleward energy-transporting role.

\subsection{Impacts of strain heating}

The evolution of ice-sheet geometry configuration is governed by competition between the net accumulation rate, which is climate-governed, and the divergence/convergence of gravitationally induced ice velocity, which is flowgoverned. Ice microphysical processes regulate the character of the ice flow, especially the dependence of viscosity on strain rate and temperature. For a given ice thickness, bedrock geometry and temperature profile within the ice, an equilibrium flow field is obtainable. To maintain exact balance, the flow-induced strain heating must be removed completely by reversible means. Additionally, flow caused by divergence/convergence must be exactly balanced by surface net accumulation/ablation. As a consequence, exact balance is never reached. In the following discussion of strain heating, it is assumed that a nearly balanced state exists so that the ice geometry does not vary significantly.

Strain heating can be expressed as $\frac{2}{\nu} \cdot \sigma_{\text {eff }}^{2}$ (Greve, 2005), where $\nu$ is ice viscosity and $\sigma_{\text {eff }}$ is effective stress (Pa) expressed as $\sigma_{\text {eff }}=\sqrt{\frac{1}{2} \operatorname{tr}(\sigma)^{2}}$, with tr being the trace function and $\sigma$ being the deviatoric stress tensor. Assuming constant geometry and temperature field within the ice sheet, strain heating can be expressed as $Q_{\mathrm{s}}=2 A^{-1 / n} \dot{\varepsilon}_{\mathrm{e}}{ }^{(1+1 / n)}$, where $A$ is the temperature-dependent ice fluidity, related to the activation energies for ice deformation. At the same time, $\dot{\varepsilon}_{\mathrm{e}} / A$ is a temporal constant. Thus, it is straightforward to show that, for two temperatures $T_{1}$ and $T_{2}$, the ratio of strain heating is $A\left(\mathrm{~T}_{1}\right) / A\left(T_{2}\right)$. In the derivation, enhancement factors are omitted and only the parameterization of Paterson (1994) is used.

Figure 5 shows the near upper surface (10 m depth) strainheating changes estimated according to MIROC-hires estimated atmospheric parameters. For each line segment, the starting point corresponds to the 2000 situation and the end point corresponds to the 2100 situation. The absolute values for different fast glaciers are also quite different as they depend on ice geometry. Thus, it is less meaningful to make cross comparisons between different locations. For each glacier, strain-heating values are plotted against strain heating at $-35^{\circ} \mathrm{C}$. The $A(T)$ curve is also plotted to provide a reference. Integrating the ice model with the SRES A1B scenario until 2100, we find that ice temperatures at Jakobshavn, Petermann, Kangerdlugssuaq and Helheim glaciers, Summit and Southern Dome increase by 1.8, 3.7, $2.8,3,2.42$ and $2.6^{\circ} \mathrm{C}$ respectively over the 100 year period. As a result, for Petermann Glacier, the strain-heating rate, in the near surface at $10 \mathrm{~m}$ depth, will almost double by 2100 . Strain-heating rates at Jakobshavn and Kangerdlugssuaq glaciers are already quite high, but will increase as the temperature increases (there is a $\sim 80 \%$ increase from 2000 to 2100). Increased strain heating will be significant over all the GrlS, so as long as the air temperature keeps increasing, the strain-heating rate also increases.

The 'grade-glacier' theory (Hallet and others, 1996 and references therein; Alley and others, 2003) generalizes silt production and transportation as an integrated component of ice erosion on the glacier bed. It shows that climate fluctuations, by modifying ice surface slope, can affect sediment transport and erosion patterns. This theory partially motivated the granular basal sliding treatment because the established warming climate may flatten the marginal area of the fast glaciers surrounding the GrIS and encourage the deposition of granular sediments. This is a positive feedback because granular basal sliding enhances ice divergence to downstream locations which are not in equilibrium even with current climate conditions, and hence the ice melts rapidly. The meltwater thus generated enhances granular 
material production. The detailed parameterization of granular material viscosity can be found in Ren and others (2010, 2011a,b). This erosion positive feedback explains why the fast glaciers usually have bedrock elevations lower than the surrounding regions (ice lying in trenches) and usually are below sea level (e.g. H., J. and K. glaciers in Fig. 1). For example, the bedrock topography at Jakobshavn Isbræ may initially be a slight depression. With the positive feedback of ice viscosity enhancement (the larger the slope, the smaller the viscosity as time elapses), the ice speed increases and the ice flow forms a stream as it becomes narrower and more concentrated than sheet flow. As the ice flows faster, the erosion rate increases and more granular material is produced at the bottom. Granular material has a much smaller viscosity than solid ice and the flow is greatly enhanced and the generated granular material is effectively transported downstream. As these positive feedbacks continue, a deeper trench of the order of hundreds of metres is produced and the trench extends upstream. If the ice were suddenly removed, Greenland would become three major islands separated by shallow ocean waters.

\subsection{Impacts of granular basal sliding}

Granular material can be widely available under an ice sheet because, during the glacier's history, around the grounding line repeated phase changes between ice and water are highly effective mechanisms for producing granular material. The process is several orders of magnitude faster than uniform weathering by runoff water. To study ice-sheet flow, granular material under solid ice is less important than that located under a melting base. To first order, the subglacial geochemical environment consists of finely crushed rocks bathed in ice melt, analogous to the flowthrough reactors used to measure mineral weathering rates (Anderson, 2006). For SEGMENT-ice, the input parameters are granular layer thickness and effective grain size. Obtaining the granular layer thickness is difficult because both the production rates and the subglacial flow washout rate are required (Cutler, 2006). With sufficient surface iceflow observations and known ice temperature distributions, the granular parameters can be objectively retrieved by the data assimilation routine of SEGMENT-ice. The retrieved granular material thickness and effective size are used only as initial conditions. Their subsequent evolution is parameterized according to Anderson (2006), using an erosion scheme with temperature- and geology-dependent multiplicative factors.

\subsection{Case study: Jakobshavn Isbræ}

Jakobshavn Isbræ lies at the intersection of the three positive feedbacks described in the preceding subsections. From Figure 1, if the ice is completely removed, Greenland becomes three islands separated by shallow ocean waters. Geologically, Jakobshavn Isbræ is located in the valley between the largest middle island (containing the Summit, SMT in Fig. 1) and the southern island (containing the Southern Dome, SD). The largest surface slope angle is $\sim 9^{\circ}$ at $1 \mathrm{~km}$ resolution, one of the steepest surface slopes on the GrIS. At the interface with ocean water, there is $\sim 550 \mathrm{~m}$ deep ice below sea level and the width of the mouth is $\sim 6 \mathrm{~km}$ (hence the vertical cross section is $\sim 3 \mathrm{~km}^{2}$ at the ocean/ice interface). Because of its southern location $\left(69^{\circ} \mathrm{N}\right)$, the ice temperature is relatively high, with a surface annual mean temperature of about $-10^{\circ} \mathrm{C}$.

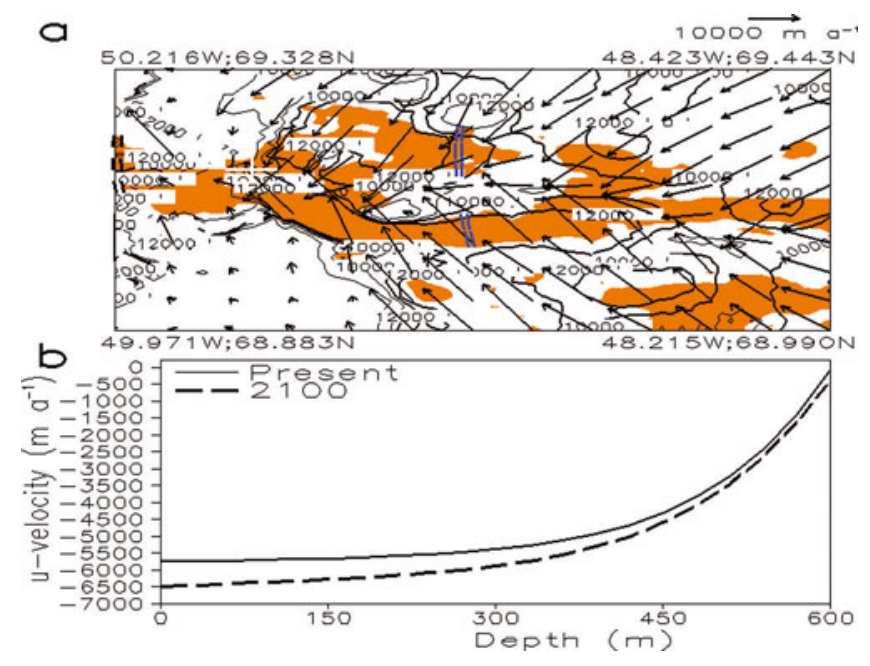

Fig. 6. SEGMENT-ice simulation of the ice flow field at Jakobshavn Isbræ (red box in Fig. 1). (a) Year 2000 surface (u, v) velocity. (b) The $u$-velocity profile at a point near the mouth (ice/ocean interface, ' + ' in (a)) for 2000 and a projected 2100 profile (dashed line). Ice flow is faster in 2100 because the ice temperature is higher; the back force from ocean hydrostatic pressure is lower because the tongue thins as ocean melting increases, and there is increased granular basal sliding speed. Including ice-thickness changes, the discharge rate at the mouth of Jakobshavn Isbræ has increased by $\sim 1.2 \mathrm{~km}^{3} \mathrm{a}^{-1}(\sim 5 \%$ of year 2000 value) by $2100.1 \mathrm{~km}$ resolution ice geometry data are used in the model simulation. Meteorological fields for the projection are from CCSM3 under the SRES A1B scenario.

A model simulation of the entire GrlS was made at $1 \mathrm{~km}$ horizontal resolution, but only the flow changes between 2000 and 2100 for the Jakobshavn Isbræ vicinity are shown here (Fig. 6). Meteorological forcing parameters are from CCSM3 under the SRES A1B scenario emissions assumption. Figure $6 \mathrm{a}$ is a model-simulated present-day surface level iceflow velocity, and Figure $6 \mathrm{~b}$ shows the flow vertical profile changes over the 2000-2100 period, near the bottleneck leading to the present mouth $\left({ }^{\prime}+\right.$ ' in Fig. 6a). The flow is concentrated, and maximum velocity cores indicate primarily westward speeds of $>8000 \mathrm{~m} \mathrm{a}^{-1}$. In addition to the positive feedback of granular basal sliding, the concentrated ice flow arises from the steep bedrock geometry and the reduction in ice viscosity. Because of the large magnitude of flow divergence/convergence, large fluctuations in ice geometry adjustment are expected, on decadal timescales. However, ocean discharge will always be significant. We show a limited simulation domain $(49.97 \mathrm{~W}, 68.883 \mathrm{~N}$ at the left lower corner to $48.42 \mathrm{~W}, 69.44 \mathrm{~N}$ at the right upper corner). Viewed from the entire GrlS, this ice stream drains a large sector of the ice sheet $(\sim 7 \%$ of the total area). Integration along the ocean/ice interface of the cross product of ice velocity and unit normal of the interface indicates that the present ice speeds supply $\sim 23 \mathrm{~km}^{3} \mathrm{a}^{-1}$ to the ocean.

There is an expected increase in flow speeds in the $21 \mathrm{st}$ century (Fig. 6b), as a result of interactions between ocean warming, air warming and increased granular basal sliding. Ice surface elevation over this small area is insignificant because of a dynamic equilibrium between increased ice discharge and the increased ice flow at the upper stream source region. Compared with the year 2000 level, annual ice discharge into the ocean could increase by $\sim 1.4 \mathrm{~km}^{3} \mathrm{a}^{-1}$ ( $\sim 5 \%$ of the present annual rate) by 2100 . The grounding line is steadily retreating. By 2050 the ice/ocean interface 
may retreat to the ' + ' sign location, and by 2100 to the location of the double dashed blue line. Because of the complicated bedrock topography, the ice/ocean interface may be separated into two segments by 2100 (Fig. 6a). The southern branch has deeper $(1000 \mathrm{~m})$ ice layers lying below sea level than the wider, northern branch, which has $<100 \mathrm{~m}$ ice lying below sea level. Also the ice speed is larger for the southern branch $\left(\sim 8500 \mathrm{ma}^{-1}\right)$ than the northern branch $\left(700 \mathrm{ma}^{-1}\right)$. Hence the ice/sea interaction is primarily through the southern branch. The southeast areas below sea level (right lower corner in Fig. 6a) cannot interact with the ocean water in the transient climate change period as they have no direct connection to the ocean.

Ice thickness near the mouth is $\sim 600 \mathrm{~m}$. At the bottom, basal sliding contributes a sliding speed of $\sim 90 \mathrm{ma}^{-1}$ at present, increasing to $\sim 400 \mathrm{~m} \mathrm{a}^{-1}$ by 2100 (Fig. 6b). The ice velocity profile within the thin $(\sim 1 \mathrm{~m})$ granular layer is dilatant, but flow is shear-thinning above that layer. The $300 \mathrm{~m} \mathrm{a}^{-1}$ increase thus adds almost uniformly to the $600 \mathrm{~m}$ thick ice.

\section{DISCUSSION}

The three positive feedback mechanisms examined in this study have all been shown in Section 3 to be significant in the 21 st century. Hitherto, each has been neglected in ice modelling but they all are important and contribute in an interactive manner to the total ice melting. Therefore, this study of GrlS melting has included all three processes and has estimated their impacts.

In the case of positive feedbacks from oceanic interactions with ice, we consider oceanic effects, through their poleward energy transport and the associated influences on weather patterns relevant to the GrIS surface mass balance. The direct oceanic role on the GrIS is limited, as its interface with water accounts for a small fraction of the current GrIS. More importantly, most outlets will be land-terminated as the climate warms, as they are on timescales much shorter than the AMOC feedback. On even longer geological timescales such as $10^{6}$ year timescales, which are still below Milankovitch's orbital scale, land-sea reconfiguration from tectonic movement may cause closing/opening of seaways and have significant effects on ice age (Molnar, 2008). The potential for large earthquakes and tsunamis must also be considered when addressing oceanic effects on global energetics and their relevance to climate change. However, such considerations are beyond the scope of this study.

Turning to the second positive feedback process, strain heating is a distributed heating source that heats the ice from inside. Generally, strain-heating rate is largest near the bottom. As the climate warms, the air temperature increases and precipitation also tends to increase; this is a consensus feature of all the IPCC AR4 archived general circulation models. For ice sheets, these are heating sources at the upper boundary. As the near-surface ice warms, the ice viscosity reduces but the ice flow increases more dramatically, to maintain balance with the gravitational driving, and the strain-heating rate therefore increases. The heat caused by strain heating warms the ice layer immediately beneath the surface layer. As this layer's temperature increases, flow speeds in the layer increase to maintain a balance with gravitational driving of the entire overlying ice, and strainheating rate also increases. This thermomechanically coupled mechanism transfers heat more effectively and provides a pathway much quicker than pure heat diffusion. Heat diffusion is ineffective for the long-distance transfer of heat because, to effectively transfer heat away from a source, a temperature gradient must be maintained. Maintaining a steady temperature gradient over a long distance (several kilometres) is not practical in natural conditions. For example, to keep a $25 \mathrm{Wm}^{-2}$ heat flow within an ice column, a steady $10 \mathrm{~K} \mathrm{~m}^{-1}$ temperature gradient is necessary. It is impossible to keep this temperature even over a $30 \mathrm{~m}$ depth. However, the GrIS has $80 \%$ of its area deeper than $2 \mathrm{~km}$. By coupling with strain heating, the heat transfer is more effective.

The effects of the third positive feedback, that of granular material on ice flow, are not discussed in detail here as a full discussion is given in Ren and others (2011a). The granular enhancement of ice flow therefore is persistent, as it exists whenever there is an ice sheet present.

\section{CONCLUSIONS}

In this study, the melting of the GrIS during the 20th and 21st centuries and the underlying mechanisms are investigated. A new ice-dynamics model, SEGMENT-ice, is employed, forced by monthly atmospheric and oceanic conditions provided by high-resolution CGCMs.

Three mechanisms that have positive feedbacks on ice melting are described and assessed: oceanic interactions at the interface, strain heating and granular basal sliding. Each mechanism is significant and increases exponentially as the temperature increases. Ice melting caused by oceanic interactions, although important and of the same order of magnitude as sensible heat flux from the atmosphere, is not persistent and also is not universal for the GrlS. Less than $0.1 \%$ of the ice grounding line is marine-terminating. More importantly, in the expected future climate-warming conditions, fast glaciers that are currently marine-terminating may become completely land-terminated and the direct ocean effects will then disappear completely. This changing role of ocean-ice interactions is exemplified by the case study, in Section 3.4, of the evolution of Jakobshavn Isbræ during the 21 st century. Jakobshavn Isbræ begins with all three processes being important, but when the links between the ocean and the glacier cease, only two remain important: strain heating and basal sliding. Strain heating and granular basal sliding effects remain as both are more pervasive than oceanic interactions because they continue for as long as the ice sheets exist.

\section{ACKNOWLEDGEMENTS}

This work is supported by the Australian Sustainable Development Institute, Curtin University, Perth. We acknowledge the international modeling groups for providing their data for analysis, and the Program for Climate Model Diagnosis and Intercomparison (PCMDI) for collecting and archiving the model data. Transient climate simulations under SRES A1B were obtained from the PCMDI Coupled Model Intercomparison Project (CMIP). These simulations were run as part of a coordinated series of simulations by the modelling centres for the IPCC Fourth Assessment Report. We thank Aixue $\mathrm{Hu}$ for useful discussions about the Bering Strait opening and closing during the last glacial period. 


\section{REFERENCES}

Alley, R.B. 2000. The Younger Dryas cold interval as viewed from central Greenland. Quat. Sci. Rev., 19(1-5), 213-226.

Alley, R.B., D.E. Lawson, G.J. Larson, E.B. Evenson and G.S. Baker. 2003. Stabilizing feedbacks in glacier-bed erosion. Nature, 424(6950), 758-760.

Anderson, S.P. 2006. Impact of mineral surface area on solute fluxes at Bench Glacier, Alaska. In Knight, P.G., ed. Glacier science and environmental change. Malden, MA, Blackwell, 79-81.

Bamber, J.L., S. Ekholm and W.B. Krabill. 2001. A new, highresolution digital elevation model of Greenland fully validated with airborne laser altimeter data. J. Geophys. Res., 106(B4), 6733-6745.

Bersch, M., I. Yashayaev and K.P. Koltermann. 2007. Recent changes of the thermohaline circulation in the subpolar North Atlantic. Ocean Dyn., 57(3), 223-235.

Bindschadler, R.A. 2006. Hitting the ice sheets where it hurts. Science, 311(5768), 1720-1721.

Broecker, W.S., D.M. Peteet and D. Rind. 1985. Does the oceanatmosphere system have more than one stable mode of operation? Nature, 315(6014), 21-26.

Collins, W.D. and 14 others. 2006. The Community Climate System Model Version 3 (CCSM3). J. Climate, 19(11), 2122-2143.

Cutler, P.M. 2006. Modelling impact of glacier-permafrost interaction on subglacial water flow. In Knight, P.G., ed. Glacier science and environmental change. Maldon, MA, Blackwell.

Genthon, C. 1994. Antarctic climate modeling with general circulation models of the atmosphere. J. Geophys. Res., 99(D6), 12,953-12,961.

Glen, J.W. 1955. The creep of polycrystalline ice. Proc. R. Soc. London, Ser. A, 228(1175), 519-538.

Greve, R. 2005. Relation of measured basal temperatures and the spatial distribution of the geothermal heat flux for the Greenland ice sheet. Ann. Glaciol., 42, 424-432.

Häkkinen, S. 2007. Upper ocean T-S variations in the Greenland Sea and their association to climatic conditions. J. Geophys. Res., 112(C7), C07004. (10.1029/2006JC003498.)

Hallet, B., L.E. Hunter and J. Bogen. 1996. Rates of erosion and sediment evacuation by glaciers: a review of field data and their implications. Global Planet. Change, 12(1-4), 213-235.

Hasumi, H. and S. Emori, eds. 2004. K-1 coupled GCM (MIROC) description. Tokyo, University of Tokyo. Centre for Climate System Research. (K-1 Model Developers Tech. Rep. 1.)

Hay, W.W., J.L. Sloan and C.N. Wold. 1988. Mass/age distribution and composition of sediments on the ocean floor and the global rate of sediment subduction. J. Geophys. Res., 93(B12), 14,933-14,940.

Hay, W.W., C.A. Shaw and C.N. Wold. 1989. Mass-balanced paleogeographic reconstructions. Geol. Rundsch., 78(1), 207-242.

Hooke, R.LeB. 1981. Flow law for polycrystalline ice in glaciers: comparison of theoretical predictions, laboratory data, and field measurements. Rev. Geophys. Space Phys., 19(4), 664-672.

Howat, I.M., I.R. Joughin and T.A. Scambos. 2007. Rapid changes in ice discharge from Greenland outlet glaciers. Science, 315(5818), 1559-1561.

$\mathrm{Hu}, \mathrm{A}$. and 8 others. 2010. Influence of Bering Strait flow and North Atlantic circulation on glacial sea-level changes. Nature Geosci., 3(2), 118-121.

Huang, B., Z.-Z. Hu and B. Jha. 2007. Evolution of model systematic errors in the Tropical Atlantic Basin from coupled climate hindcasts. Climate Dyn., 28(7-8), 661-682.

Jop, P., Y. Forterre and O. Pouliquen. 2006. A constitutive law for dense granular flows. Nature, 441(7094), 667-784.

Joughin, I., W. Abdalati and M.A. Fahnestock. 2004. Large fluctuations in speed on Greenland's Jakobshavn Isbræ glacier. Nature, 432(7017), 608-610.
Karstensen, J., P. Schlosser, D.W.R. Wallace, J.L. Bullister and J. Blindheim. 2005. Water mass transformation in the Greenland Sea during the 1990s. J. Geophys. Res., 110(C7), C07022. (10.1029/2004JC002510.)

MacAyeal, D.R. 1992. Irregular oscillations of the West Antarctic ice sheet. Nature, 359(6390), 29-32.

Manabe, S. and R.J. Stouffer. 1999. The role of thermohaline circulation in climate. Tellus, 51A-B(1), 91-109.

Meehl, G.A. and 12 others. 2007. Global climate projections. In Solomon, S. and 7 others, eds. Climate change 2007: the physical science basis. Contribution of Working Group I to the Fourth Assessment Report of the Intergovernmental Panel on Climate Change. Cambridge, etc., Cambridge University Press, 747-845.

Molnar, P. 2001. Climate change, flooding in arid environments, and erosion rates. Geology, 29(12), 1071-1074.

Molnar, P. 2008. Closing of the Central American Seaway and the Ice Age: a critical review. Paleoceanography, 23(1), PA2201. (10.1029/2007PA001574.)

Myers, P.G., N. Kulan and M.H. Ribergaard. 2007. Irminger water variability in the West Greenland Current. Geophys. Res. Lett., 34(17), L17601. (10.1029/2007GL030419.)

Nick, F.M., A. Vieli, I.M. Howat and I. Joughin. 2009. Large-scale changes in Greenland outlet glacier dynamics triggered at the terminus. Nature Geosci., 2(2), 110-114.

Ohmura, A., M. Wild and L. Bengtsson. 1996. A possible change in mass balance of Greenland and Antarctic ice sheets in the coming century. J. Climate, 9(9), 2124-2135.

Oka, A. and H. Hasumi. 2004. Effects of freshwater forcing on the Atlantic Deep Circulation: a study with an OGCM forced by two different surface freshwater flux datasets. J. Climate, 17(11), 2180-2194.

Paterson, W.S.B. 1994. The physics of glaciers. Third edition. Oxford, etc., Elsevier.

Peterson, B.J., J. McClelland, R. Curry, R.M. Holmes, J.E. Walsh and K. Aagaard. 2006. Trajectory shifts in the Arctic and subarctic freshwater cycle. Science, 313(5790), 1061-1066.

Ren, D. and 7 others. 2009. Mudslide-caused ecosystem degradation following Wenchuan earthquake 2008. Geophys. Res. Lett., 36(5), L05401. (10.1029/2008GL036702.)

Ren, D., R. Fu, D.J. Karoly, L.M. Leslie, J. Chen and C.R. Wilson. 2010. A new ice sheet model validated by remote sensing of the Greenland ice sheet. Cent. Eur. J. Geosci., 2(4), 501-513.

Ren, D., R. Fu, L.M. Leslie, D.J. Karoly, J. Chen and C. Wilson. 2011a. A multirheology ice model: formulation and application to the Greenland ice sheet. J. Geophys. Res., 116(D5), D05112. (10.1029/2010JD014855.)

Ren, D., R. Fu, L.M. Leslie, J. Chen, C.R. Wilson and D.J. Karoly. 2011b. The Greenland Ice Sheet response to transient climate change. J. Climate, 24(13), 3469-3483.

Richter, I. and S.-P. Xie. 2008. On the origin of equatorial Atlantic biases in coupled general circulation models. Climate Dyn., 31(5), 587-598.

Rignot, E., M. Koppes and I. Velicogna. 2010. Rapid submarine melting of the calving faces of West Greenland glaciers. Nature Geosci., 3(3), 141-218.

Rignot, E., I. Velicogna, M.R. van den Broeke, A. Monaghan and J. Lenaerts. 2011. Acceleration of the contribution of the Greenland and Antarctic ice sheets to sea level rise. Geophys. Res. Lett., 38(5), L05503. (10.1029/2011GL046583.)

Saenger, C., P. Chang, L. Ji, D.W. Oppo and A.L. Cohen. 2009. Tropical Atlantic climate response to low-latitude and extratropical sea-surface temperature: a Little Ice Age perspective. Geophys. Res. Lett., 36(11), L11703. (10.1029/2009GL038677.)

Serreze, M.C. and 9 others. 2006. The large-scale freshwater cycle of the Arctic. J. Geophys. Res., 111(C11), C11010. (10.1029/ 2005JC003424.)

Shapiro, N.M. and M.H. Ritzwoller. 2004. Inferring surface heat flux distribution guided by a global seismic model: particular application to Antarctica. Earth Planet. Sci. Lett., 233(1-2), 213-224. 
Stearns, L.A. and G.S. Hamilton. 2007. Rapid volume loss from two East Greenland outlet glaciers quantified using repeat stereo satellite imagery. Geophys. Res. Lett., 34(5), L05503. (10.1029/ 2006GL028982.)

Stocker, T.F. 2002. North-south connections. Science, 297(5588), 1814-1815.

Stouffer, R.J. and 22 others. 2006. Investigating the causes of the response of the thermohaline circulation to past and future climate changes. J. Climate, 19(8), 1365-1287.

Straneo, F. and 7 others. 2010. Rapid circulation of warm subtropical waters in a major glacial fjord in East Greenland. Nature Geosci., 3(33), 182-186.

Thierry, V., E. de Boisséson and H. Mercier. 2008. Interannual variability of the Subpolar Mode Water properties over the Reykjanes Ridge during 1990-2006. J. Geophys. Res., 113(C4), C04016. (10.1029/2007JC004443.)

Thomas, R.H. 2004. Force-perturbation analysis of recent thinning and acceleration of Jakobshavn Isbræ, Greenland. J. Glaciol., 50(168), 57-66.
Thomas, R.H. and 8 others. 2000. Substantial thinning of a major east Greenland outlet glacier. Geophys. Res. Lett., 27(9), 1291-1294.

Van der Veen, C.J. 1999. Fundamentals of glacier dynamics. Rotterdam, A.A. Balkema.

Velicogna, I. 2009. Increasing rates of ice mass loss from the Greenland and Antarctic ice sheets revealed by GRACE. Geophys. Res. Lett., 36(19), L19503. (10.1029/2009GL040222.)

Vellinga, M. and P. Wu. 2004. Low-latitude freshwater influence on centennial variability of the Atlantic thermohaline circulation. J. Climate, 17(23), 4498-4511.

Wang, W.L. and R.C. Warner. 1999. Modeling of anisotropic ice flow in Law Dome, East Antarctica. Ann. Glaciol., 29, 184-190.

Williams, P.D. 2011. The RAW filter: an improvement to the Robert-Asselin filter in semi-implicit integrations. Mon. Weather Rev., 139(6), 1996-2007.

Zwinger, T., R. Greve, O. Gagliardini, T. Shiraiwa and M. Lyly. 2007. A full Stokes-flow thermo-mechanical model for firn and ice applied to the Gorshkov crater glacier, Kamchatka. Ann. Glaciol., 45, 29-37.

MS received 13 April 2011 and accepted in revised form 5 September 2011 